\title{
Influence of melt treatments and polished CVD diamond coated insert on cutting force and surface integrity in turning of $\mathrm{Al}-7 \mathrm{Si}$ and Al-7Si-2.5Cu cast alloys
}

\author{
K G BASAVAKUMAR*, P G MUKUNDA ${ }^{\dagger}$ and M CHAKRABORTY ${ }^{\dagger}$ \\ Department of Mechanical Engineering, Sri Bhagwan Mahavir Jain College of Engineering, Bangalore 562 112, India \\ ${ }^{\dagger}$ Department of Metallurgical and Materials Engineering, Indian Institute of Technology, Kharagpur 721 302, India
}

MS received 11 October 2006

\begin{abstract}
The microstructures, machinability and surface characteristics of $\mathrm{Al}-7 \mathrm{Si}$ and $\mathrm{Al}-7 \mathrm{Si}-2 \cdot 5 \mathrm{Cu}$ cast alloys were studied after various melt treatments like grain refinement and modification. The results indicate that combined grain refined and modified $\mathrm{Al}-7 \mathrm{Si}-2 \cdot 5 \mathrm{Cu}$ cast alloys have microstructures consisting of uniformly distributed $\alpha$-Al grains, eutectic $\mathrm{Al}$-silicon and fine $\mathrm{CuAl}_{2}$ particles in the interdendritic region. These alloys exhibited better machinability and surface characteristics in the cast condition compared with the same alloy subjected to only grain refinement or modification. Performances of the turning inserts (uncoated and polished CVD diamond coated) were evaluated in machining $\mathrm{Al}-7 \mathrm{Si}$ and $\mathrm{Al}-7 \mathrm{Si}-2 \cdot 5 \mathrm{Cu}$ cast alloys under dry environment using a lathe. The polished CVD diamond coated insert outperformed the uncoated cutting insert which suffered from sizeable edge buildup leading to higher cutting force and poor surface finish. The polished CVD diamond coated insert shows a very small steady wear without flaking of the diamond film during cutting. This paper attempts to investigate the influence of grain refinement, modification and combined action of both on the microstructural changes in the $\mathrm{Al}-7 \mathrm{Si}$ and $\mathrm{Al}-7 \mathrm{Si}-2 \cdot 5 \mathrm{Cu}$ cast alloys and their machinability and surface finish when different turning inserts are used.
\end{abstract}

Keywords. Grain refinement; modification; machining; Al-7Si; $\mathrm{Al}-7 \mathrm{Si}-2 \cdot 5 \mathrm{Cu}$ cast alloys.

\section{Introduction}

The reason for the wide acceptance of Al-Si alloys can be found in the attractive combination of physical properties and generally excellent castability, mechanical properties, corrosion resistance, machinability, hot tearing resistance, fluidity and weldability. Hence, Al-Si alloys are widely used in automobile, aerospace, defence and general engineering industries (Mondolfo 1979; ASM Handbook 1989a,b).

At present, the cemented carbide inserts alone or with TiN, TiC or TiN + TiC, or PCD coatings are used for turning applications. The high hardness, wear resistance and chemical stability of these inserts with proven benefits in terms of tool life, good surface finish and reduced cutting force are well known. However, cutting tool performance is found wanting in machining materials like $\mathrm{Al}-\mathrm{Si}$ alloys, whose use is increasing in the expanding automobile industry. The cutting tools suffer from rapid wear because of strong adhesion and chemical reaction with Al-Si alloys. In contrast, diamond coating can provide anti-welding characteristics because of chemical inertness towards $\mathrm{Al}-\mathrm{Si}$

\footnotetext{
*Author for correspondence (ganukb@rediffmail.com)
}

alloys. This can also offer remarkable abrasive wear resistance because of its super hardness. CVD diamond insert is an outstanding candidate for dry machining due to its unique properties such as low coefficient of friction, high thermal conductivity, high-temperature hardness and chemical stability. Further surface modification of diamond coated tools by polishing helps in further reducing cutting forces and improving surface finish of the dry machined components (Konig and Erinski 1983; Malshe et al 1999; Prabhu et al 2006).

The present state of technology for material cutting is characterized by the high productivity of precise components achieved by computer-controlled high-power machines. The success of this operation depends in no less degree on the proper choice of cutting tools. A very important finding is that alloys with the same chemical composition can have different microstructures and mechanical properties due to variations in the casting process, the use of a grain refiner, modifier, or both grain refiner and modifier and also by heat treatment. This means that different processing techniques can result in a range of mechanical properties which affect the cutting process (Grum and Kisin 2005).

It was in the 1960 s that researchers first showed that a high-quality machined surface can be achieved by looking at all the aspects of the problem, including microstructure 
studies. Studies of the surface quality produced by a machining process of aluminum alloys confirmed that. A particular characteristic of the two-phase and multiphase microstructures of Al-Si alloys is the matrix phase which is always soft and highly ductile whereas the second phase is considerably harder. For a good surface finish, it is important that the particles of the hard phase are very fine and uniformly distributed within the soft aluminium base (Grum and Kisin 2003).

The surface roughness achieved during turning depends on the size, size distribution and morphology of the silicon particles, which, in turn, depends on the soft-phase deformation in the surface layer. Studies showed a relation between the microstructure of the alloy and the roughness of the machined surface, i.e. a relation with the magnitude of the variation of the cutting force after turning. It was found that an increase in the size of the soft matrix grains produced an increase in the cutting force and the roughness of the machined surface (Chamberlain 1979; Brechet et al 1991).

The machinability and surface characteristics of $\mathrm{Al}-7 \mathrm{Si}$ and $\mathrm{Al}-7 \mathrm{Si}-2 \cdot 5 \mathrm{Cu}$ cast alloys mainly depend on the shape, size and size distribution of the $\alpha$-Al grains, eutectic morphology and $\mathrm{CuAl}_{2}$ particles in the interdendritic region. The microstructure of $\mathrm{Al}-7 \mathrm{Si}$ and $\mathrm{Al}-7 \mathrm{Si}-2 \cdot 5 \mathrm{Cu}$ cast alloys consists of large primary $\alpha$-Al grains, the eutectic silicon (plate-like) and massive $\mathrm{CuAl}_{2}$ particles in the interdendritic region showing poor ductility in casting. Unmodified acicular silicon acts as internal stress risers in the microstructure and provides easy path for fracture. With the addition of grain refiners and modifiers, it converts large elongated primary $\alpha-\mathrm{Al}$ grains into fine equiaxed $\dot{\alpha}-\mathrm{Al}$ grains and eutectic silicon (plate-like) into fine particles and fine $\mathrm{CuAl}_{2}$ particles in the interdendritic region resulting in the improved machinability and surface finish characteristics (Kori et al 2000; Basavakumar et al 2006).

Several experimental results have been reported describing the use of grain refiners and modifiers to obtain a fine-grained microstructure of hypoeutectic Al-Si alloys. The effect of grain refinement and/or modification and combined addition of both on the machinability and surface characteristics of $\mathrm{Al}-7 \mathrm{Si}$ and $\mathrm{Al}-7 \mathrm{Si}-2 \cdot 5 \mathrm{Cu}$ cast alloys have not yet been sufficiently elucidated, except for hardness, and tensile properties. The purpose of the present study was to improve the machinability of $\mathrm{Al}-7 \mathrm{Si}$ and $\mathrm{Al}-7 \mathrm{Si}-2 \cdot 5 \mathrm{Cu}$ cast alloys using grain refiner and/or modifier, combined addition of both and different turning inserts (uncoated and polished CVD diamond coated).

\section{Experimental}

Al-7Si alloy was prepared by melting commercially pure aluminum $(99.7 \%)$ with $\mathrm{Al}-20 \% \mathrm{Si}$ master alloy in clay graphite crucible in a pit type resistance furnace under a cover flux $(45 \% \mathrm{NaCl}+45 \% \mathrm{KCl}+10 \% \mathrm{NaF})$ and the melt was held at $720^{\circ} \mathrm{C}$. After degassing with $1 \%$ solid hexachloroethane, master alloy chips duly packed in aluminum foil were added to the melt for grain refinement. For modification, Al-10\%Sr master alloy was used with addition level being kept constant at $0.02 \mathrm{wt} \% \mathrm{Sr}$ (Kori et al 2000). The melt was stirred for $30 \mathrm{~s}$ after the addition of grain refiner and/or modifier. Melts were held for $5 \mathrm{~min}$ and poured into a cylindrical graphite mould surrounded by fireclay brick. The details of the alloys, grain refinement and modification treatment and mechanical properties of various alloys are given in table 1 . The chemical compositions of the cast alloys and master alloys assessed using atomic emission spectroscopy are given in table 2. The microstructures of the samples that had been cut in the longitudinal direction were studied. Grain size analysis was carried out by the linear intercept method after etching the polished surface with Keller's reagent $(2.5 \%$ $\mathrm{HNO}_{3}, 1.5 \% \mathrm{HCl}, 1 \% \mathrm{HF}$ and $95 \% \mathrm{H}_{2} \mathrm{O}$ ). Samples for optical microscopy were electro polished using an electrolytic bath comprising of $80 \%$ methanol and $20 \% \mathrm{HNO}_{3}$ by volume. Selected samples were subjected to SEM and XRD analyses.

Machinability tests were carried out on $\mathrm{Al}-7 \mathrm{Si}$ and $\mathrm{Al}-$ 7 $\mathrm{Si}-2 \cdot 5 \mathrm{Cu}$ cast alloys (cylindrical rods) using lathe under dry environment with constant feed rate $(0.2 \mathrm{~mm} / \mathrm{rev})$, constant cutting speed $(226 \mathrm{~m} / \mathrm{min})$ and constant depth of cut $(0.4 \mathrm{~mm})$ for uncoated and polished CVD diamond coated turning inserts. The details of turning inserts data for

Table 1. Test specimens and analysed mechanical properties of Al-7Si and Al-7Si-2.5Cu alloys.

\begin{tabular}{lllcccc}
\hline Sl. no. & Alloy designation & \multicolumn{1}{c}{ Alloy composition } & $\begin{array}{c}\text { Addition level } \\
\text { of GR (wt\%) }\end{array}$ & $\begin{array}{c}\text { Addition level of } \\
\text { modifier (wt\%) }\end{array}$ & $\begin{array}{c}\text { UTS } \\
(\mathrm{MPa})\end{array}$ & $\begin{array}{c}\text { Hardness } \\
(\mathrm{HB})\end{array}$ \\
\hline 1 & $\mathrm{HP}-1$ & $\mathrm{Al}-7 \mathrm{Si}$ & - & - & 149 & 60 \\
2 & $\mathrm{HP}-2$ & $\mathrm{Al}-7 \mathrm{Si}-1 \mathrm{M} 13$ & $1 \cdot 0$ & - & 160 & 66 \\
3 & $\mathrm{HP}-3$ & $\mathrm{Al}-7 \mathrm{Si}-0 \cdot 02 \mathrm{Sr}$ & - & $0 \cdot 02$ & 168 & 70 \\
4 & $\mathrm{HP}-4$ & $\mathrm{Al}-7 \mathrm{Si}-2 \cdot 5 \mathrm{Cu}$ & - & - & 163 & 73 \\
5 & $\mathrm{HP}-5$ & $\mathrm{Al}-7 \mathrm{Si}-2 \cdot 5 \mathrm{Cu}-1 \mathrm{M} 13$ & $1 \cdot 0$ & $0 \cdot 02$ & 184 & 85 \\
6 & $\mathrm{HP}-6$ & $\mathrm{Al}-7 \mathrm{Si}-2 \cdot 5 \mathrm{Cu}-0 \cdot 02 \mathrm{Sr}$ & - & $0 \cdot 02$ & 194 & 90 \\
7 & $\mathrm{HP}-7$ & $\mathrm{Al}-7 \mathrm{Si}-2 \cdot 5 \mathrm{Cu}-0 \cdot 02 \mathrm{Sr}-1 \mathrm{M} 13$ & $1 \cdot 0$ & 200 & 98 \\
\hline
\end{tabular}

GR: Grain refiner $(\mathrm{M} 13=\mathrm{Al}-1 \mathrm{Ti}-3 \mathrm{~B})$; modifier [(Sr-strontium) $]$ 
Table 2. Chemical analysis of cast alloys and master alloys.

\begin{tabular}{lrccccc}
\hline & \multicolumn{7}{c}{ Composition (wt\%) } \\
\cline { 2 - 7 } Alloy & \multicolumn{1}{c}{$\mathrm{Si}$} & $\mathrm{Fe}$ & $\mathrm{Sr}$ & $\mathrm{Ti}$ & $\mathrm{B}$ & $\mathrm{Al}$ \\
\hline Al & $0 \cdot 11$ & $0 \cdot 16$ & - & - & - & Balance \\
Al-7Si & $6 \cdot 98$ & $0 \cdot 17$ & - & - & - & Balance \\
Al-10Sr & $0 \cdot 12$ & $0 \cdot 17$ & $10 \cdot 0$ & - & - & Balance \\
Al-20Si & $20 \cdot 13$ & $0 \cdot 18$ & - & - & - & Balance \\
Al-1Ti-3B & $0 \cdot 16$ & $0 \cdot 17$ & - & $1 \cdot 13$ & $2 \cdot 25$ & Balance \\
Al-5Ti-3B & $0 \cdot 15$ & $0 \cdot 17$ & - & $5 \cdot 62$ & 1.04 & Balance \\
\hline
\end{tabular}

Table 3. Detailed data of turning inserts for machining

\begin{tabular}{ll}
\hline & \multicolumn{1}{c}{ Insert code: CCGT 09T304 FL K10 } \\
\hline $\mathrm{C}$ & Shape of insert $-80^{\circ}$ \\
$\mathrm{C}$ & Clarence angle $-7^{\circ}$ \\
$\mathrm{G}$ & Tolerance \\
$\mathrm{T}$ & Type \\
09 & Cutting edge length, $\mathrm{mm}$ \\
$\mathrm{T} 3$ & Thickness, 3.97 $\mathrm{mm}$ \\
04 & $0 \cdot 4 \mathrm{~mm}$ \\
$\mathrm{FL}$ & Chipbraker \\
K-10 & Carbide grade \\
Uncoated insert-K-10: 94\%WC $+6 \% \mathrm{CO}$ \\
Polished CVD diamond coated, $R_{\mathrm{a}}, 0 \cdot 14-0 \cdot 16 \mu \mathrm{m}$ \\
\hline
\end{tabular}

the present work and geometry of the inserts are given in table 3. Tangential cutting force, $P_{\mathrm{z}}(N)$, and axial force, $P_{\mathrm{x}}(N)$, were measured at suitable intervals using a Kistler Piezoelectricity lathe tool dynamometer, mounted together with the cutting-tool handle on a transverse support of the experimental lathe.

Surface roughness of machined alloys under different conditions were evaluated using $R_{\mathrm{a}}(\mu \mathrm{m})$ and $R_{\mathrm{z}}(\mu \mathrm{m})$ parameters with the help of surface roughness tester (Mitutoyo SJ-301, Japan) under the following conditions: Standard: ISO 1999; profile: $R$; cut off length: $0.8 \mathrm{~mm}$; range: auto; speed: $0.25 \mathrm{~mm} / \mathrm{s} ; R_{\mathrm{a}}$ : average roughness; $R_{\mathrm{z}}$ : maximum peak height.

\section{Results and discussion}

\subsection{Microstructures of $\mathrm{Al}-7 \mathrm{Si}$ and $\mathrm{Al}-7 \mathrm{Si}-2 \cdot 5 \mathrm{Cu}$ cast alloys treated by grain refiner and modifier}

The microstructures of the $\mathrm{Al}-7 \mathrm{Si}$ and $\mathrm{Al}-7 \mathrm{Si}-2 \cdot 5 \mathrm{Cu}$ cast alloys before and after grain refinement, modification and combined addition of both refiners and modifier are shown in figure $1(\mathrm{a}-\mathrm{g})$. It is observed that grain refinement, modification and combined addition of both refiner and modifier have profound influence on microstructures of the $\mathrm{Al}-7 \mathrm{Si}$ and $\mathrm{Al}-7 \mathrm{Si}-2 \cdot 5 \mathrm{Cu}$ cast alloys. Figure $1(\mathrm{a}$ and $\mathrm{d})$ shows the microstructure of untreated alloys consisting of large primary $\dot{\alpha}-\mathrm{Al}$ grains (soft phase), the plate-like eutectic silicon (eutectic) and massive $\mathrm{CuAl}_{2}$ particles in the interdendritic region. Figure $1(\mathrm{~b}$ and e) shows the micro- structures of treated ( $1 \mathrm{wt} \% \mathrm{Al}-1 \mathrm{Ti}-3 \mathrm{~B}$ grain refiner) alloys consisting of fine equiaxed $\dot{\alpha}-\mathrm{Al}$ grains (soft phase), unmodified eutectic and $\mathrm{CuAl}_{2}$ particles in the interdendritic region. Figure 1(c and $\mathrm{f}$ ) shows the microstructure of treated $(0.02 \mathrm{wt} \% \mathrm{Sr}$ modifier) alloys consisting of few primary $\dot{\alpha}$-Al grains (soft phase), uniformly distributed fine eutectic mixture (eutectic) and fine $\mathrm{CuAl}_{2}$ particles in the interdendritic region.

Figure 1(g) shows the microstructure treated by the combined addition of both grain refiner and modifier $(1 \mathrm{wt} \%$ Al-1Ti-3B grain refiner and $0.02 \mathrm{wt} \% \mathrm{Sr}$ modifier) alloys consisting of fine equiaxed $\dot{\alpha}-\mathrm{Al}$ grains (soft phase), uniformly distributed fine eutectic mixture and fine $\mathrm{CuAl}_{2}$ particles in the interdendritic region.

The present experimental work confirms that, addition of grain refiner $(1 \mathrm{wt} \% \mathrm{Al}-1 \mathrm{Ti}-3 \mathrm{~B})$ to $\mathrm{Al}-7 \mathrm{Si}$ and $\mathrm{Al}-$ $7 \mathrm{Si}-2 \cdot 5 \mathrm{Cu}$ alloy significantly refines the coarse columnar primary $\alpha$-Al grains to fine equiaxed $\alpha$-Al grains due to the presence of $\mathrm{AlB}_{2} / \mathrm{TiB}_{2}$ particles present in the master alloy which are nucleating agents during the solidification of $\dot{\alpha}$-Al grains (soft phase), while the eutectic silicon particles appear to be unaffected as expected. Also the addition of modifier $(0.02 \mathrm{wt} \% \mathrm{Sr})$ to $\mathrm{Al}-7 \mathrm{Si}$ and $\mathrm{Al}-$ $7 \mathrm{Si}-2 \cdot 5 \mathrm{Cu}$ alloy changes the plate-like eutectic silicon to uniformly distributed fine particles (eutectic) and fine $\mathrm{CuAl}_{2}$ particles in the interdendritic region (Basavakumar et al 2006). The results also suggest that the addition of $\mathrm{Al}-1 \mathrm{Ti}-3 \mathrm{~B}$ master alloy along with $\mathrm{Sr}$ modifier to $\mathrm{Al}-7 \mathrm{Si}$ and $\mathrm{Al}-7 \mathrm{Si}-2 \cdot 5 \mathrm{Cu}$ cast alloys shows more uniformly distributed $\alpha$-Al grains, fine silicon and $\mathrm{CuAl}_{2}$ particles in the interdendritic region compared to the individual addition of grain refiner or modifier. It is important to note that the alloys have been cast in a graphite mould surrounded by fireclay brick (slow cooling). Thus, further improvement in the machinability and surface characteristics can be expected for fast cooled castings, as this can lead to further refinement of the microstructures.

Figure 2(a) shows the distribution of the intercept lengths, $L \dot{\alpha}$, measured for the grains of soft phase for untreated $\mathrm{Al}-7 \mathrm{Si}-2 \cdot 5 \mathrm{Cu}$ alloy. On the basis of measurements of the longest length and shortest length, 15 classes were determined, with the width of a single class being $10 \mu \mathrm{m}$. From the data in the column chart, it is clear that the fraction of grains of solid phase, $L \dot{\alpha}$, with size up to 90 $100 \mu \mathrm{m}$ is as high as $80 \%$. The microstructure also shows 

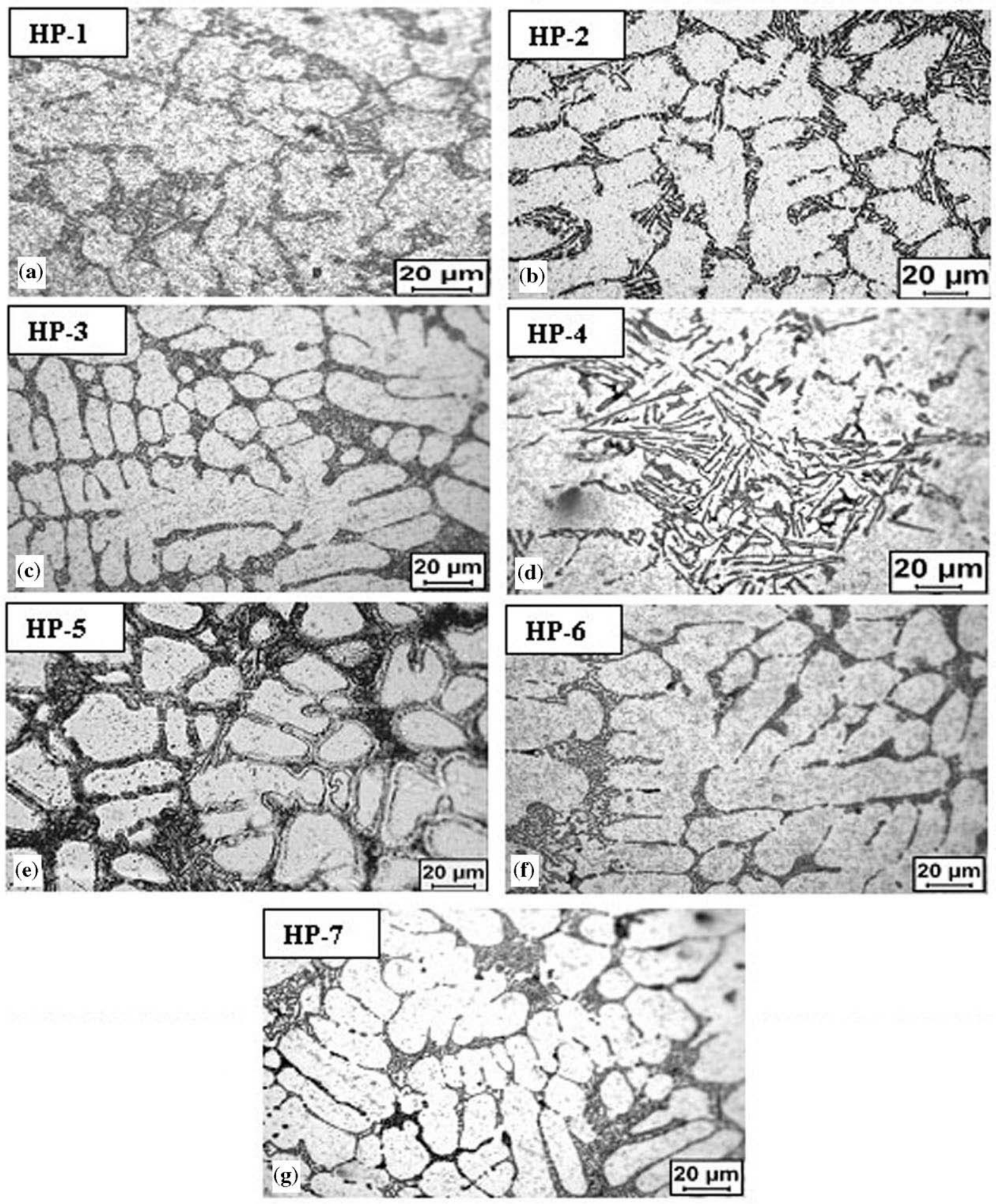

Figure 1. Optical microphotographs of Al-7Si alloy (a) un-treated, (b) with grain refiner (1\% of M13), (c) with modifier $(0.2 \% \mathrm{Sr})$ and $\mathrm{Al}-7 \mathrm{Si}-2.5 \mathrm{Cu}$ alloy, (d) untreated, (e) with grain refiner $(1 \%$ of M13), (f) with modifier $(0 \cdot 2 \%$ $\mathrm{Sr})$ and $(\mathbf{g})$ with grain refiner ( $1 \%$ of M13) and modifier $(0.02 \% \mathrm{Sr})$.

a few large primary coarser grains with intercept lengths between 130 and $150 \mu \mathrm{m}$. The size distribution of the measured intercept lengths for the eutectic constituent, $E p$, of the untreated $\mathrm{Al}-7 \mathrm{Si}-2 \cdot 5 \mathrm{Cu}$ alloy is shown in figure 2(b). In the size range up to $60-70 \mu \mathrm{m}$, there are as many as $80 \%$ of the eutectic, which means that the eutectic of the untreated hypoeutectic alloy is coarse and plate-like particles. 

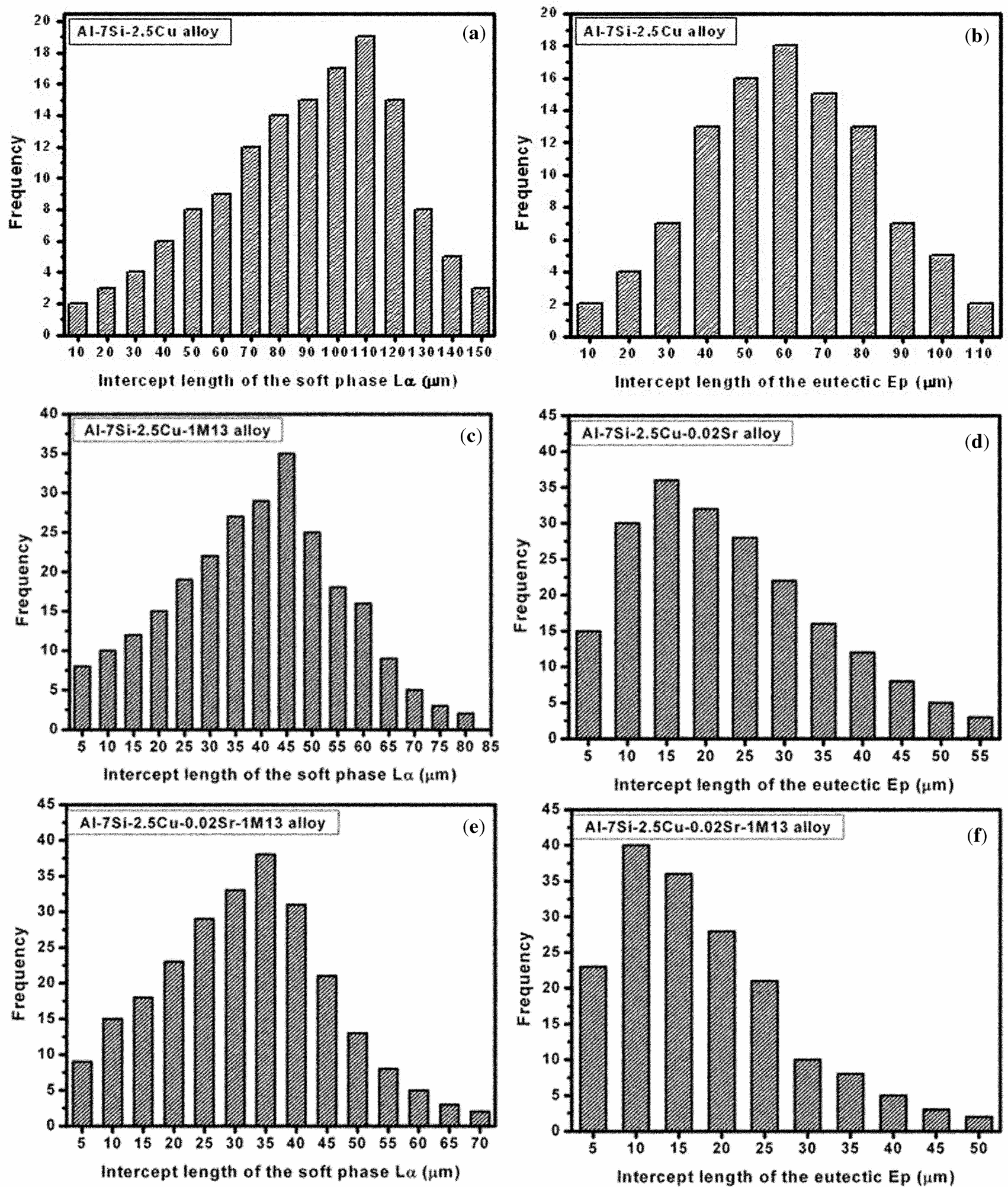

Figure 2. Frequency of the intercept lengths of (a) soft phase, $L \dot{\alpha}$, (b) eutectic, $E_{\mathrm{p}}$, for the untreated hypoeutectic alloy, (c) soft phase, $L \dot{\alpha}$, (d) eutectic, $E_{\mathrm{p}}$, for the treated hypoeutectic alloy, (e) soft phase, $L \dot{\alpha}$ and (f) eutectic, $E_{\mathrm{p}}$, for the combined treated hypoeutectic alloy.

Figure 2(c) shows distribution of the intercept lengths, $L \dot{\alpha}$, measured for the grains of soft phase for grain refined
(1 wt \% Al-1Ti-3B) Al-7Si-2.5Cu alloy. The bandwidth of a single class is only $5 \mu \mathrm{m}$. In the size range up to $40-45 \mu \mathrm{m}$, 
there are as many as $85 \%$ of all grains measured, which means that the soft phase of the hypoeutectic alloy is fine and equiaxed.

The size distribution of the measured intercept lengths for the eutectic, Ep, of the modified $(0.02 \mathrm{wt} \% \mathrm{Sr}) \mathrm{Al}-$ $7 \mathrm{Si}-2 \cdot 5 \mathrm{Cu}$ alloy is shown in figure $2(\mathrm{~d})$. In the size range up to $10-15 \mu \mathrm{m}$, there are as many as $85 \%$ of all measured intercept lengths for the eutectic, which means that the eutectic of the treated hypoeutectic alloy is fine and uniformly distributed.

Figure 2(e and f) shows the distribution of $L \dot{\alpha}$ measured for the grains of soft phase and eutectic $E p$ for the combined grain refined and modified ( $1 \mathrm{wt} \% \mathrm{Al}-1 \mathrm{Ti}-3 \mathrm{~B}$ and $0.02 \mathrm{wt} \% \mathrm{Sr}$ ) $\mathrm{Al}-7 \mathrm{Si}-2.5 \mathrm{Cu}$ alloy. It is clear that the fraction of grains of soft phase, $L \dot{\alpha}$, with size up to 35$40 \mu \mathrm{m}$ is as high as $80 \%$ and the fraction of eutectic $E p$ with size up to $10-15 \mu \mathrm{m}$ is as high as $85 \%$, which means that figure 2(e and $\mathrm{f}$ ) clearly reveals fine equiaxed grains (soft phase) together with fine modified eutectic.

\subsection{Influence of microstructural changes on cutting forces}

During turning there are two processes occurring simultaneously in the cutting zone: material cutting that produces a chip and plastic deformation of the chip and the workpiece material in the surface layer. Both processes have a synergic influence on the formation of the chip and of the new workpiece surface, which can be described by changes of the cutting force. Although all the Al-Si alloys involved differ a little in their mechanical properties, they show a distinct difference in the cutting force under identical cutting conditions. The differences may arise from different cutting conditions, increased wear, changes in the tool geometry, and differences in the alloy microstructures. The behaviour of the hypoeutectic alloy in the cutting zone and the changes in the component of the cutting force depend on the changes and size of the $\dot{\alpha}$-Al grains (soft phase) and the eutectic.

3.2a Untreated alloys: Untreated $\mathrm{Al}-7 \mathrm{Si}$ and $\mathrm{Al}-7 \mathrm{Si}-$ $2 \cdot 5 \mathrm{Cu}$ alloys consist of longest lengths of both soft and eutectic which produce changes in the periodic variations of the cutting force. It is known that an increase in the fraction of the solid-solution grains in the alloy will significantly increase the probability of formation of deposits produced by the workpiece material at the cutting face of the tool. The solid solution is soft and plastic; therefore, in the course of turning it will adhere to the cutting face of the tool. The deposit will gradually increase in size and, when it exceeds a critical size, it will separate from the cutting face and adhere to the lower surface of the chip. Thus, in the course of cutting, material will gradually accumulate to a certain thickness at the cutting face. The deposit at the cutting face will produce a change in the tool geometry, which is indicated by an increase of the cutting force (figure 3 ). It is assumed that at the moment when the deposit reaches the critical size it will slide, under the action of a sufficiently strong transverse force, completely or partly from the cutting face and be eliminated with the chip. It can be assumed that at this moment the measured cutting force will attain its peak value. Due to the turning conditions another case may occur when a deposit from the tool face slides over the cutting nose and imprints into the already-machined workpiece surface. Immediately after the elimination of the existing deposit, a new deposit will form on the tool, and will gradually grow and change the tool geometry, which will result in further increase of the cutting force.

3.2b Combined influence of grain refiner and modifier: Given the statistical data on the microstructure of the Al$7 \mathrm{Si}-2 \cdot 5 \mathrm{Cu}$ cast alloys treated by the combined addition of both figures 2(e) and (f), it can be assumed that the conditions for the formation and shaping of a chip in the cutting zone will be completely different from those occurring in the case of the untreated alloy. With the combined addition of both, the behaviour of the workpiece material in the cutting zone and the changes in the main cutting force will depend on both constituents of the soft phase and eutectic. Due to the addition of both grain refiner and modifier, both phases are very fine and uniformly distributed. The average intercept lengths for the soft phase and eutectic are $\sim 35-40 \mu \mathrm{m}$ and $10-15 \mu \mathrm{m}$. This means that the alloy microstructure in the cutting zone is very fine grained and shows periodic stacking, i.e. a homogeneous and alternating distribution of the fine lamellae of the eutectic silicon and of the soft solid solution. Consequently, during cutting there are very favourable conditions for the formation of a chip.

Figure 3 shows the cutting force during the turning of the treated alloy. A simple visual assessment of the signal of the cutting force indicates that there are no individual, distinct maximum amplitudes, i.e. they are considerably lower and uniform than those measured for the untreated alloy. The effect of other additions like only grain refiner $(\mathrm{Al}-1 \mathrm{Ti}-3 \mathrm{~B})$ and only modifier $(\mathrm{Sr})$ on machinability properties of hypoeutectic alloys is also shown in figure 3 . Single additions have limited effect only.

\subsection{Influence of microstructural changes on surface roughness}

In the course of turning, the microstructure in the cutting zone of the thin surface layer changed because of a pronounced micro plastic deformation of the soft phase when a new surface was being formed. A microstructure analysis of the surface layer of the individual specimens confirmed that when the new surface was being formed a number of processes occured in the cutting zone, like micro plastic 

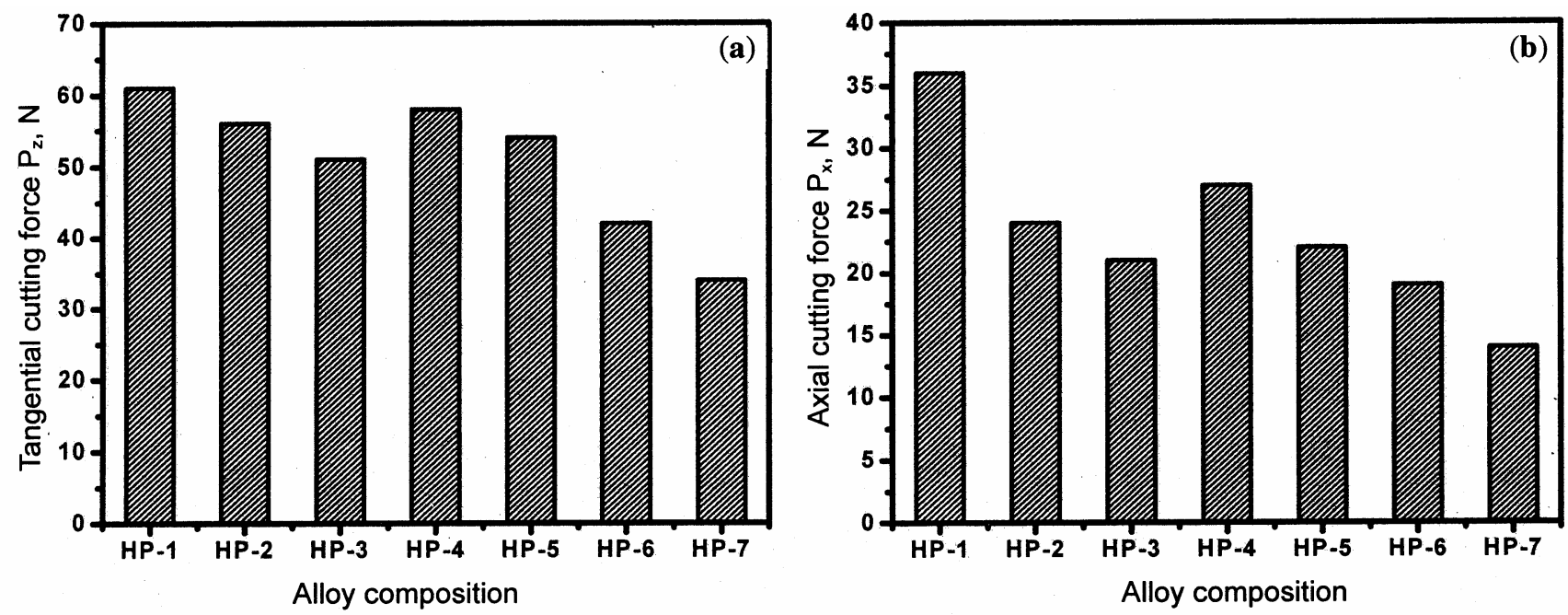

Figure 3. Variation of (a) tangential cutting force, $P_{\mathrm{z}}$ and (b) axial cutting force, $P_{\mathrm{x}}$, with alloy compositions for polished CVD diamond coated insert.
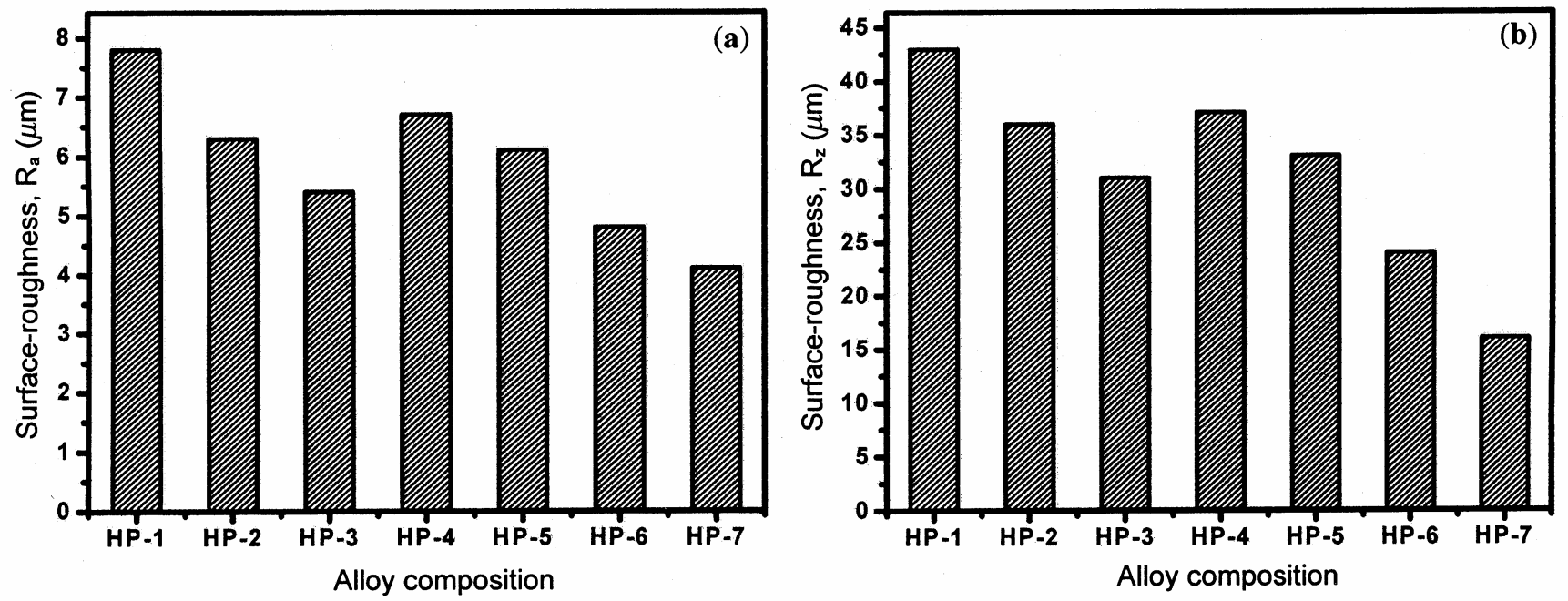

Figure 4. Variation of (a) surface roughness, $R_{\mathrm{a}}$ and (b) surface roughness, $R_{\mathrm{z}}$, with alloy compositions for polished CVD diamond coated insert.

deformation of the Al-base soft phase; adhering of the soft phase to the cutting face of a tool; adhering of the soft phase to the already machined surface; gradual removal of the built-up edge fragments by chips; and crushing of the brittle eutectic silicon.

Pronounced changes in the newly formed surface and in the microstructure of the subsurface layer occur after turning of the untreated alloys. In the course of turning the soft aluminum deformed excessively and adhered to the cutting face of the tool. During turning the built-up edge fragment at the cutting face increased. Consequently, the tool geometry changed. When the built-up edge fragment has grown to its critical size, it will slip away with a chip or adhere to the machined workpiece surface increasing the roughness of the new surfaces. For a description of the surface quality after turning, it is common to select the mean arithmetic surface roughness, $R_{\mathrm{a}}(\mu \mathrm{m})$ and $R_{\mathrm{z}}(\mu \mathrm{m})$. In the technical literature, the surface roughness is most often related only to influences of machining conditions. Consequently, influence of the microstructure on surface formation during turning was considered in the present study.

The column charts in figure 4 show the average roughness, $R_{\mathrm{a}}(\mu \mathrm{m})$ and $R_{\mathrm{z}}(\mu \mathrm{m})$, as a function of the alloy compositions. For the same machining conditions, the roughness was the highest in untreated $\mathrm{Al}-7 \mathrm{Si}$ and $\mathrm{Al}-$ $7 \mathrm{Si}-2 \cdot 5 \mathrm{Cu}$ alloys than in the grain refined, modified and combined grain refined and modified alloys. Because of pronounced plastic deformation of the soft phase in the 

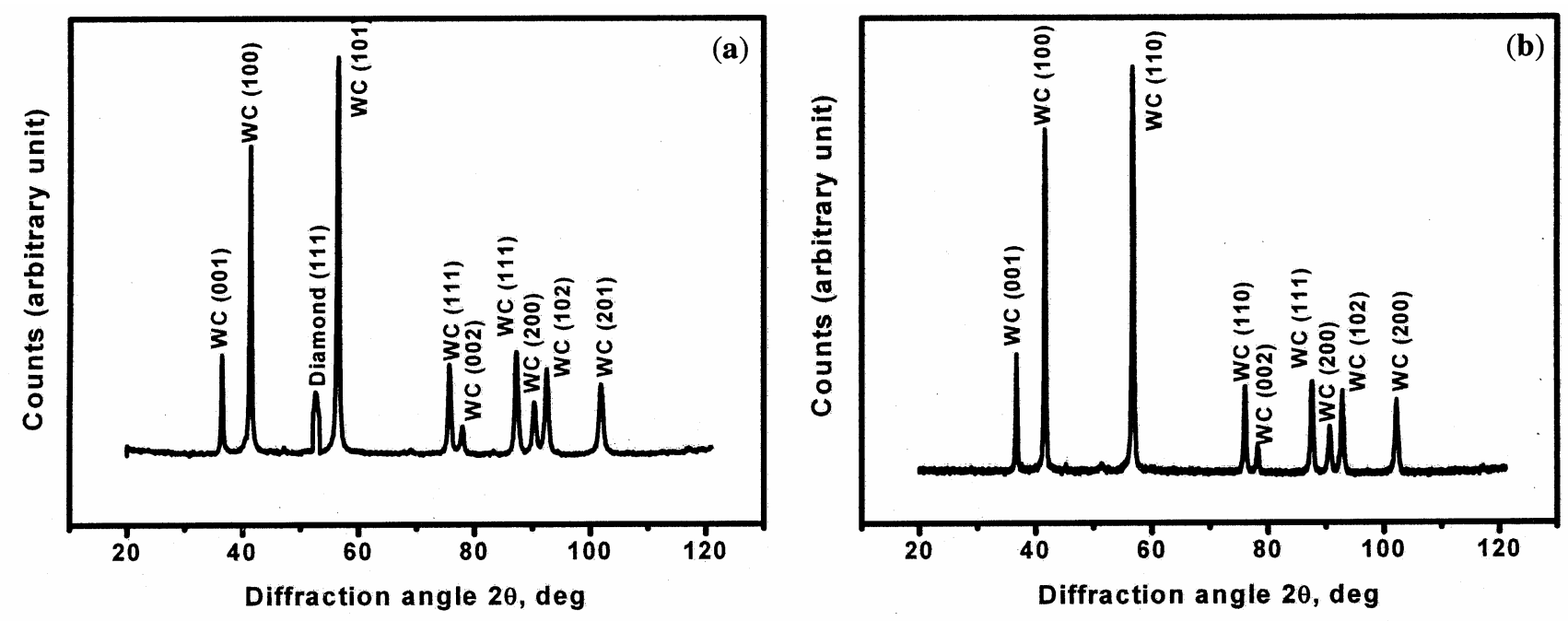

Figure 5. X-ray diffraction spectra of (a) diamond WC inserts and (b) WC insert.
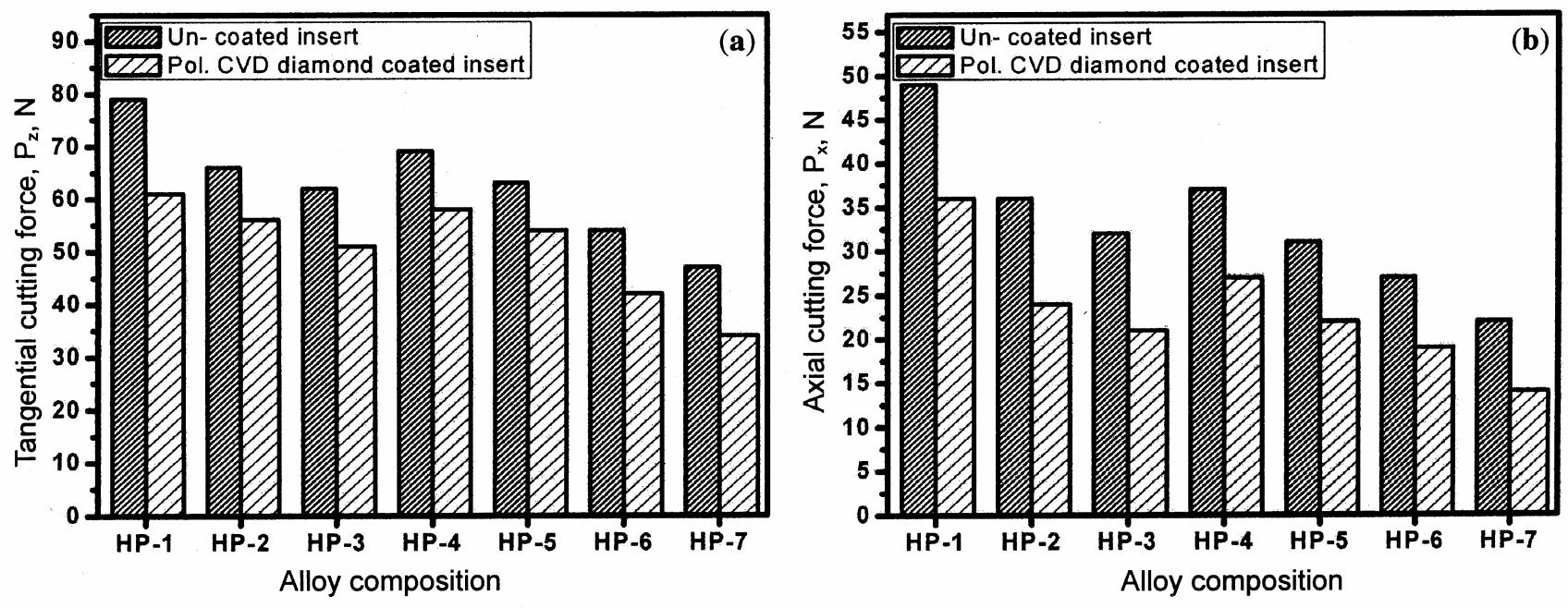

Figure 6. Variation of (a) tangential cutting force, $P_{\mathrm{z}}, \mathrm{N}$ and (b) axial cutting force, $P_{\mathrm{x}}, \mathrm{N}$ with different inserts for different alloy compositions.

Table 4. Initial roughness of the inserts.

\begin{tabular}{llcc}
\hline S1. & \multicolumn{1}{c}{ Insert } & $\begin{array}{c}\text { Roughness, } \\
R_{\mathrm{a}}(\mu \mathrm{m})\end{array}$ & $\begin{array}{c}\text { Roughness, } \\
R_{\mathrm{z}}(\mu \mathrm{m})\end{array}$ \\
\hline 1 & Uncoated & $0 \cdot 17$ & $0 \cdot 82$ \\
2 & Polished CVD diamond & $0 \cdot 14$ & 0.19 \\
\hline
\end{tabular}

cutting zone and build-up at the cutting tool edge, resulted in increased roughness of the new surface formed. The surface roughness, i.e. $R_{\mathrm{a}}=7 \cdot 8 \mu \mathrm{m}$, for polished CVD diamond insert was twice as high than that of the combined grain refined and modified alloy. Combined grain refined and modified alloy was characterized by the shortest intercept lengths of the soft phase and eutectic in the matrix.
The effect of other additions like only grain refiner (Al$1 \mathrm{Ti}-3 \mathrm{~B})$ and only modifier ( $\mathrm{Sr}$ ) on surface roughness of eutectic alloys is also shown in figure 4 and these have limited effect only.

\subsection{Influence of turning inserts on cutting force and surface roughness}

The existence of diamond coating (CVD insert) has been confirmed by X-ray diffractograms shown in figure 5(a). Figure 5(b) is the diffractogram of uncoated tool showing only WC. The faint peak of diamond as compared to WC peaks is due to the thinness of the coating. Table 4 gives the initial roughness of the inserts. 

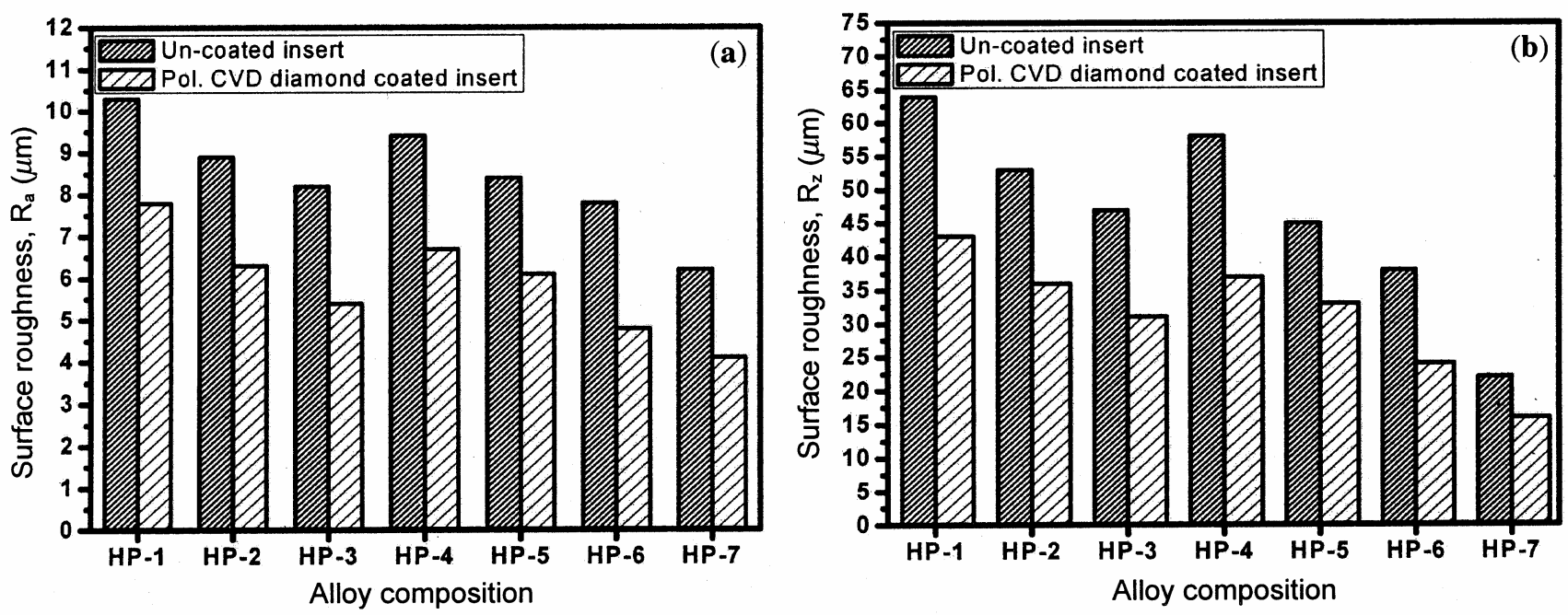

Figure 7. Variation of (a) surface roughness, $R_{\mathrm{a}}$ and (b) surface roughness, $R_{\mathrm{z}}$, with different inserts for different alloy compositions.
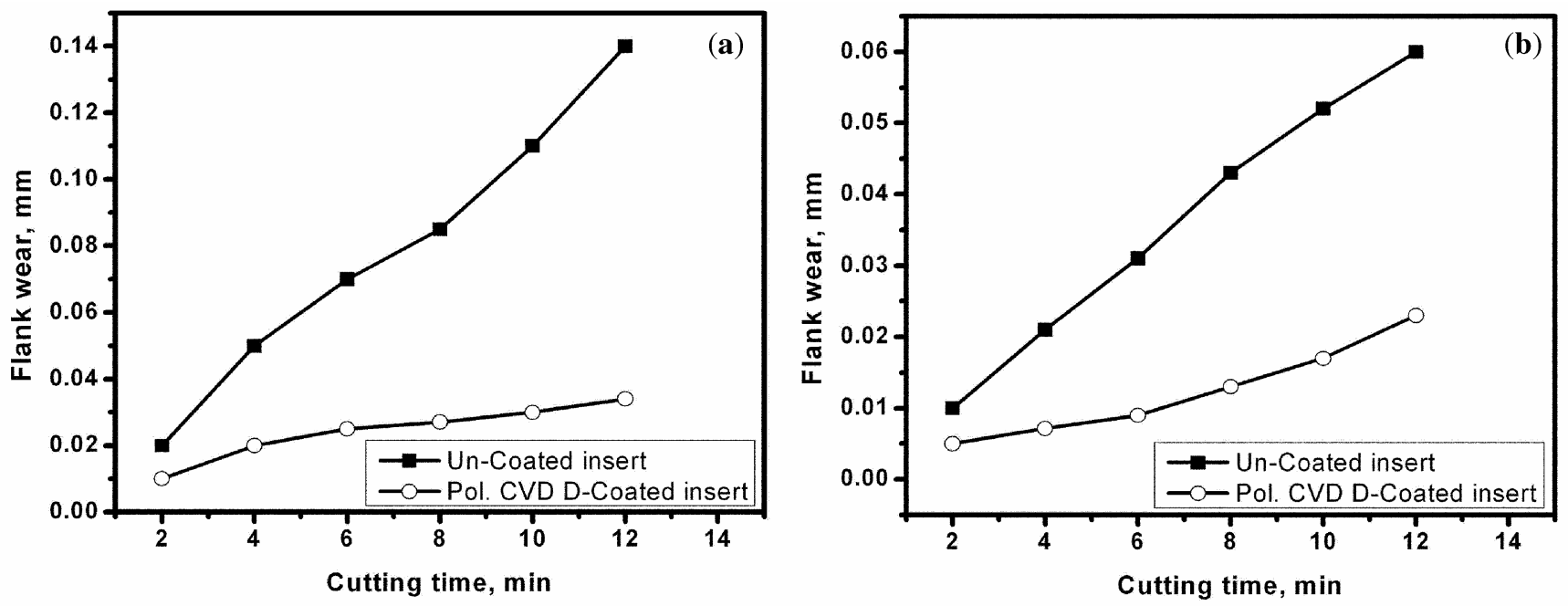

Figure 8. Flank wear in machining of (a) Al-7Si and (b) Al-7Si-2 $5 \mathrm{Cu}-0 \cdot 02 \mathrm{Sr}-\mathrm{IM} 13$ cast alloys.

The flank wear of the inserts were measured using optical microscope (MG Olympus Tokyo, Japan). The influence of grain refinement and modification on the machinability and surface finish of $\mathrm{Al}-7 \mathrm{Si}$ and $\mathrm{Al}-7 \mathrm{Si}-2 \cdot 5 \mathrm{Cu}$ cast alloys with different turning inserts (uncoated and polished CVD diamond coated) with constant cutting speed $(226 \mathrm{~m} / \mathrm{min})$, feed rate $(0.2 \mathrm{~mm} / \mathrm{rev})$ and depth of cut $(0.4 \mathrm{~mm})$ are shown in figures $6(\mathrm{a})$ and (b). It is noticeable from figures 6(a) and (b) that the tangential cutting forces $\left(P_{\mathrm{z}}\right)$ and axial cutting force $\left(P_{\mathrm{x}}\right)$ for uncoated insert appear to be high. In contrast, the cutting forces for polished CVD diamond coated insert were substantially low as shown in figures 6(a) and (b). Such low cutting forces for polished diamond coated insert could be attributed to the poor affinity of diamond to materials like $\mathrm{Al}-\mathrm{Si}$ alloys.
Surface roughness values, $R_{\mathrm{a}}$ and $R_{\mathrm{z}}$, for machined surface produced by uncoated insert were observed to be high as shown in figures 7(a) and (b). On the other hand, surface roughness of the work piece produced by the polished CVD diamond-coated insert was very low as shown in figures 7(a) and (b). Interestingly (i) polished CVD diamond coated insert continued to give a glossy surface till 12-14 min of machining after which it started giving few tear marks on the surface and (ii) polished CVD diamond-coated insert shows smooth flank wear and no flaking of the diamond film is observed at the cutting edge after 14-16 min of machining.

From figures 8(a) and (b), the initial rapid wear of polished CVD diamond-coated insert is almost the same as that for the uncoated insert but the increase in flank wear 

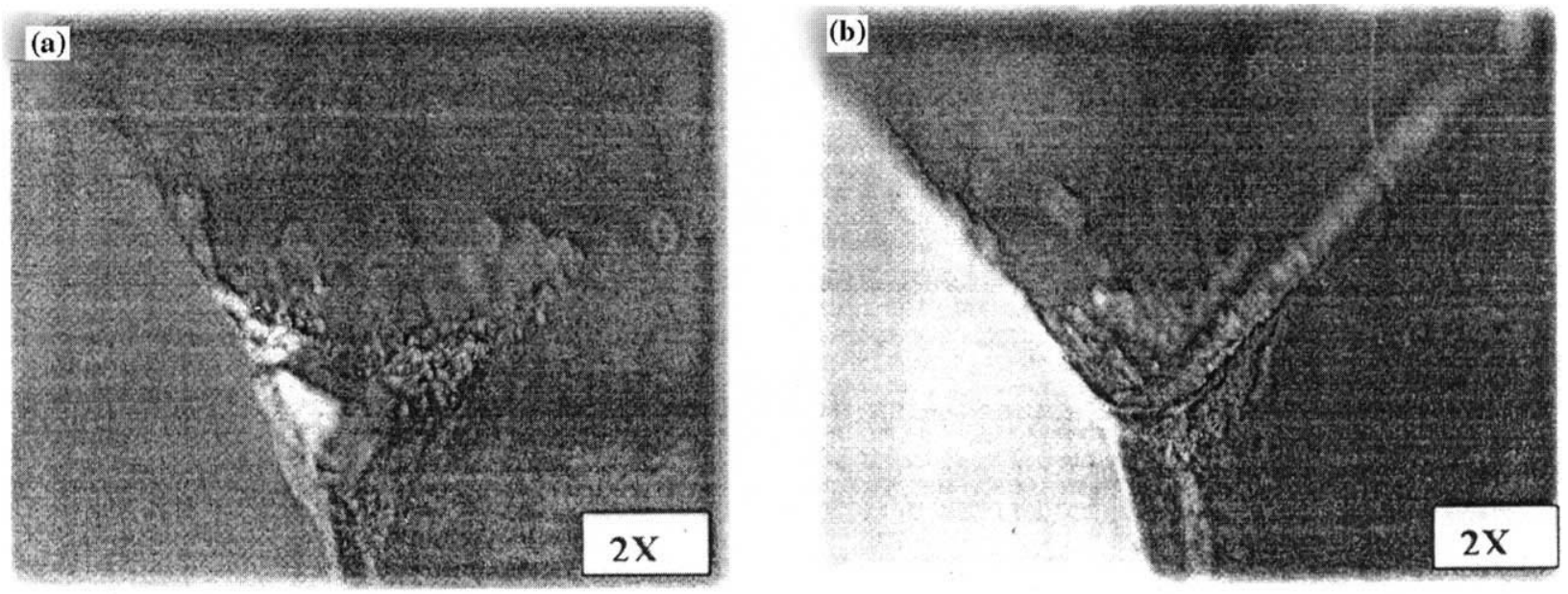

Figure 9. 3-D optical micrographs of the cutting tip after machining of Al-7Si alloy. (a) Uncoated and (b) polished CVD diamond-coated inserts.

of the polished CVD diamond-coated substrate at the steady wear stage is very small and the difference in wear compared with the uncoated insert shows remarkable increase with time. The result indicates that a polished CVD diamond-coated insert is expected to be superior for machining of Al-Si alloys.

3-D view of optical micrograph (figure 9(a)) shows heavy build-up of work-piece material on the face and flank of the uncoated insert covering the cutting edge after machining. Such good adherent layer of the work material at the tool tip is responsible for high cutting force and poorer surface finish for uncoated insert as seen in figures 7 and 8. As observed in the machining, the flowing chip moves across the rake surface and is trapped by the sharp crystallites. The trapped material build-up at and near the cutting edge would continue to grow as machining is continued, leading to the 'caterpillar effect'. At some point during cutting, enough material may sometimes be welded strongly to the uncoated insert. Alternatively, it may pile up to form a curling chip, which may be pushed back towards the work piece material at the trailing edge of the cut. If it comes in contact with the machined surface of the work piece, it may scratch and mar the surface finish. The 3-D view of optical micrograph of polished CVD diamond coated insert (figure 9(b)) shows that even after machining, the tool tip experienced no built-up edge formation. One of the advantages of such a cutting edge is a clean cutting action and a reduction in cutting forces. The polished surface allows the metal chips to slide across and away from the cutting point with relative ease, thereby preventing a curl-back or build-up near the cutting edge. It is well known that the build-up of work piece material at the cutting edge has several disadvantages: (i) it increases the cutting force, (ii) it adversely affects the surface finish of the part and (iii) it can cause severe damage to the cutting edge when the built-up material is dislodged during cutting, leading frequently to the removal of the coating or micro chipping of the cutting tool. Thus, there are several potential advantages in using polished CVD diamondcoated cutting inserts especially when machining relatively soft materials, which have a tendency to build-up at the cutting edge.

\section{Conclusions}

The effect of melt treatment and turning inserts on the machinability and surface characteristics the Al-7Si and $\mathrm{Al}-7 \mathrm{Si}-2 \cdot 5 \mathrm{Cu}$ cast alloys were investigated and the following conclusions could be drawn:

(I) Combined addition of grain refiner and modifier (Al$1 \mathrm{Ti}-3 \mathrm{~B}+\mathrm{Sr}$ ) to $\mathrm{Al}-7 \mathrm{Si}-2 \cdot 5 \mathrm{Cu}$ cast alloy shows remarkably low level of cutting forces and improved surface finish when compared with untreated alloys.

(II) The measurements performed confirmed that the principal cutting forces $\left(P_{\mathrm{z}}\right.$ and $\left.P_{\mathrm{x}}\right)$ are mainly influenced by the sizes of the soft and eutectic constituents in the alloys.

(III) The surface quality after turning was established by the measurement of roughness of the new surface formed. Average roughness, $R_{\mathrm{a}}$ and $R_{\mathrm{z}}$, increased with an increase in the sizes of the soft and eutectic constituents in the alloys.

(IV) The performance of the polished CVD diamond coated insert (in comparison to uncoated insert) in dry machining of Al-Si alloys was remarkable in that the cutting forces and the work piece surface roughness were significantly low. 
(V) The tendency for material build-up at the cutting edge is reduced when polished CVD diamond-coated insert is used. (VI) Polished CVD diamond-coated insert shows very small steady wear without flaking of the diamond film in machining hypoeutectic Al-Si alloys.

\section{References}

ASM Handbook 1989a Casting (Metals Park, Ohio: ASM International) pp 785-791

ASM Handbook 1989b Selection and properties of non-ferrous materials (Metals Park, Ohio: ASM International) Vol. 2, pp $1223-1240$

Basavakumar K G, Mukunda P G and Chakraborty M 2006 Trans. Indian Inst. Met. 59400
Brechet Y, Embury J D, Tao S and Luo L 1991 Acta Metall. \& Mater. 391781

Chamberlain B 1979 Machinability of aluminium alloys, in Metals handbook, properties and selection: nonferrous alloys and pure metals (ASTM G-4) 9th edn, Vol. 2, pp 187-190

Grum J and Kisin M 2003 Int. J. Mach. Tools \& Manu. 431535

Grum J and Kisin M 2005 Mach. Tool \& Manu. 1

Konig W and Erinski D 1983 Ann. CIRP 32535

Kori S A, Murthy B S and Chakraborthy M 2000 Mater. Sci. \& Eng. A283 94

Malshe A P, Park B S, Brown W D and Naseem H A 1999 Int. J. Diamond Relat. Mater. 81198

Mondolfo L F 1979 Aluminium: structures and properties (England: Butterworths) pp 756-775

Prabhu U A, Malshe A P and Batzer S A 2006 Int. J. Surf. \& Coating Technol. 3399 